\title{
Från vattenterapi till elchocker
}

Chockbehandlingar och andra metoder i finländsk psykiatri cirka 1900-1960

PERIODEN I900 TILL I960 VAR EN TID av stora förändringar. Urbaniseringen ledde till nya former av samhällelig verksamhet och utveckling, och teknologiska och medicinska uppfinningar gjorde livet lättare för miljontals människor. Men livet blev inte bättre för alla. Antalet mentalsjuka patienter ökade kraftigt och ett nätverk av mentalsjukhus byggdes ut i rask takt i början av I90o-talet. ${ }^{1}$ Mentalsjukhusen var på den här tiden snarare förvaringsplatser än rehabiliterande sjukhus. Effektiva behandlingsmetoder saknades och det bästa man kunde hoppas på var att den terapeutiska sjukhusmiljön och den begränsade arsenalen av behandlingsmetoder skulle åstadkomma förbättring $\mathrm{i}$ patienternas tillstånd.

Psykiatrin var länge en icke-vetenskap som saknade en stabil grund. Läkarna visste inte varför patienterna blev sjuka och än mindre visste de hur de sjuka kunde botas. Chockbehandlingarna som togs i bruk i slutet av I930-talet var revolutionerande och de var länge de enda psykiatriska vårdmetoderna som gav märkbara resultat. Ankomsten av psykofarmaka på i96o-talet innebar en övergång till andra metoder och användandet av chockbehandlingar trappades ner i rask takt.

Metoderna som uppkom på r930-talet gick under namnen insulin-, cardiazol- och elchockbehandlingar och de gick ut på att nollställa patienten genom koma eller kraftiga konvulsionsanfall. De nya metoderna åstadkom tydlig förbättring i många patienters tillstånd och väckte hopp om att sjukdomar som schizof reni och depression skulle kunna botas.

I. Petteri Pietikäinen, Hulluuden historia, Helsinki: Gaudeamus Helsinki University Press 2013, s. 160-I65, 367-368. 
Den här essän baserar sig på min avhandling pro gradu i historia, Man prövade än det ena, än det andra. Chockbehandlingar i finländsk psykiatri 1936-1964 från 2014. Materialet för avhandlingen bestod av intervjuer med läkare och sjukskötare som arbetat med chockbehandlingar, av verksamhetsberättelser från två mentalsjukhus från de berörda åren och av tio medicinska artiklar om chockbehandlingar publicerade mellan I936 och I964. Intervjuerna gjordes under våren 2012 och sommaren 20I3. Alla informanter hade inlett sin arbetskarriär inom den psykiatriska vården på I950-talet och utfört insulin- och elchockbehandlingar, eller någondera av dessa, antingen som läkare eller sjukvårdare. Sammanlagt hade de intervjuade arbetat på sju olika mentalsjukhus och sett och utfört behandlingar på dessa. ${ }^{2}$

Jag gick igenom Nickby sjukhus verksamhetsberättelser I93I-I972 och Törnävä sjukhus verksamhetsberättelser 1937-1962. Behandlingarna beskrivs väldigt kortfattat och ibland inte alls; vissa år beskrivs behandlingarna och resultaten mer ingående och andra år nämns de bara kort. I regel omnämns dock antalet chockbehandlade patienter, vilket är intressanta data i sig. ${ }^{3}$

En genomgång av samtliga nummer av de medicinska tidskrifterna Duodecim och Suomen Lääkärilehti från 1935 till 1970 gav ett material på endast nio artiklar som berör psykiatriska behandlingar. ${ }^{4}$ Under 1930- och 1940-talen fanns det cirka 80-150 läkare som arbetade med psykiatrisk vård i Finland. Många var allmänläkare och saknade utbildning i psykiatrisk medicin och därtill arbetade många ickeutexaminerade unga läkare vid sjukhusen redan under studietiden. ${ }^{5}$

2. Siiri Oinonen, Man prövade än det ena, än det andra. Chockbehandlingar i finländsk psykiatri 1936-1964, opublicerad avhandling pro gradu, Helsingfors: Helsingfors universitet 2014 .

3. Törnävä sjukhus verksamhetsberättelser I937-I962, Törnävä sjukhusmuseums bibliotek, Seinäjoki; Nickby sjukhus verksamhetsberättelser 193I-I972, Nikkilän sairaala, Dc:I Vuosikertomukset I93I-I972, Stadsarkivet, Helsingfors.

4. Oinonen, Man prövade än det ena, än det andra, s. II. Den tionde artikeln som användes i avhandlingen var Harold Bourne, "The Insulin Myth", The Lancet, vol. 262, 7/II I953, s. 964-968.

5. Enligt Ville Kivimäki, Battled Nerves. Finnish Soldiers' War Experience, Trauma, and Military Psychiatry, I94I-44, Åbo: Åbo Akademi 20I3, s. 328, fanns det i början av I940-talet ca 80 läkare med erfarenhet av psykiatrisk medicin. Enligt intervjuer, historiker och verksamhetsberättelser fanns det ungefär I läkare per Ioo-200 patienter och enligt Pietikäinen, Hulluuden historia, s. I64, fanns det år I940 ca 8400 
Undersökningsperioden för min avhandling pro gradu inleds 1936, året då insulinchockbehandling - den första formen av chockbehandling som användes i Finland - togs i bruk. År 1964 användes insulinbehandlingar för sista gången på Nickby sjukhus och eftersom det inte går att pricka in det sista året då chockbehandlingar användes i Finland i och med att elchockbehandlingar i viss mån används än i dag, valde jag detta som slutår för undersökningsperioden.

I ett 20Io-talsperspektiv kan chockbehandlingar med koma och konvulsioner verka mycket drastiska, men man bör betrakta dem som barn av sin tid. Nyckeln till att förstå behandlingarna är att förstå tidens syn på kroppskontroll och tanken om att en disciplinerad kropp är en sund kropp. Idéhistorikern Claes Ekenstam beskriver i sin bok om kroppens idéhistoria hur förhållandet till människokroppen har förändrats i samhället $i$ takt med medelklassens tillväxt. Ideal om disciplin och moral blev centrala. Ekenstam hävdar att man under I8oo- och I900-talen understödde tanken om att den behärskade människan hade den bästa hälsan, vilket ledde till att hälsa och moral kopplades samman. Kroppsdisciplin och kroppskontroll sågs som tecken på hög moral och civilisation. Kroppsligt förfall och civilisatorisk nedgång sågs som motsatsen till det friska och sunda. ${ }^{6}$

Chockbehandlingar är behandlingar som utförs på kroppen. Kroppsdisciplinering ansågs leda till hälsa och moral, vilket i sin tur ledde till en medikalisering av kroppsdisciplinen. ${ }^{7}$ Genom att behandla den mentalsjuka patientens kropp åstadkom man ett friskare sinne, precis som man genom att disciplinera en frisk persons kropp åstadkom bättre moral och hälsa.

Det är viktigt att förutom fysisk kontroll även beakta frågan om social kontroll. Dels ville man möjliggöra ett så gott liv som möjligt för så många som möjligt, dels ville man ha strikta ramar för individuellt och samhälleligt välbefinnande. Industrialiseringen, urbaniseringen

patienter på de finska mentalsjukhusen. Uppskattningsvis arbetade ca 80-Ioo läkare vid sjukhusen. I och med att antalet patienter ökade under I940-talet ökade även antalet läkare. Utifrån källor och litteratur uppskattar jag att Ioo-I5o läkare arbetade på sjukhusen under denna tid.

6. Claes Ekenstam, Kroppens idéhistoria: disciplinering och karaktärsdaning $i$ Sverige I700-I950, Hedemora: Gidlund I993, s. 207, 209, 216, 236, 238.

7. Ibid., s. 298. 
och medelklassens kraftiga tillväxt gjorde civiliserat beteende och kroppslig disciplin till en samhällelig norm. Det civiliserade samhällets främsta uppgift var att bekämpa barbari, och denna uppgift kom i den västliga världen till uttryck i allt från kolonialism till nykterhetsrörelser och folkskolor. Civiliserat beteende var det normala, och alla som uppfattades avvika från normen - vare sig de var alkoholiserade analfabeter på den finska landsbygden, afrikaner som dyrkade naturgudar i kolonierna eller psykiskt sjuka stadsbor - skulle normaliseras. Michel Foucault är känd för sina teser om "den stora inspärrningen" med vilken han menade att de mentalt sjuka samlades i stora institutioner där de sedan förvarades utom synhåll för de friska medborgarna. De psykiatriska anstalterna och den psykiatriska vården kan alltså ses som ett led i den stora samhälleliga civilisationsprocessen. ${ }^{8}$

\section{CHOCKBEHANDLINGARNAS FÖREGÅNGARE}

Psykiatrins historia är fylld av besynnerliga behandlingsmetoder. Under seklernas gång har man prövat på det mesta från snurrande stolar till långa bad och kirurgiska ingrepp. Medicinen som vetenskap utvecklades snabbt från och med I8oo-talet, men undervisning i psykiatrisk medicin började förekomma först kring sekelskiftet I900. Den första professuren i psykiatri vid Helsingfors universitet tillkom I909. ${ }^{9}$ Psykiatrins anseende var inte särskilt gott och övriga läkare ansåg att psykiatrikerna inte ens kunde räknas till läkarkåren. Behandlingsmetoderna som främst baserade sig på vatten, sömn och arbete var ineffektiva och behovet av effektiva och snabba behandlingsmetoder akut. ${ }^{10}$ Utvecklingen av de till synes effektiva chockbehandlingarna ledde till entusiasm i läkarkåren. Före en närmare granskning av chockbehandlingarna tar jag kort upp de metoder som var i bruk före dem samt frågan varför antalet mentalsjuka steg i början av rgoo-talet.

8. Norbert Elias, Civilisationsteori: Del I, Sedernas historia, Stockholm: Atlantis I989, s. 132; Michel Foucault, Madness and Civilization. A History of Insanity in the Age of Reason, New York: Vintage Books 1973, s. 38-64.

9. Pietikäinen, Hulluuden bistoria, s. 80, 367-371.

Io. Pietikäinen, Hulluuden historia, s. 80; Edward Shorter, Psykiatrian historia, Helsinki: Mielenterveyden keskusliitto 2005, s. 79; Robert Whitaker, Mad in America. Bad Science, Bad Medicine and the Enduring Mistreatment of the Mentally Ill, New York: Basic Books 2010. 
Det finns inget entydigt och enkelt svar på varför antalet mentalsjuka verkar ha ökat vid sekelskiftet. Bidragande orsaker är befolkningstillväxten, ökningen av antalet mentalsjukhus och diagnostiseringens utveckling. Som en följd av urbaniseringen och det ökade antalet anstalter flyttades de sinnessjuka från familjen och hemmet till mentalsjukhus. Urbaniseringen ändrade på samhällsstrukturer och sociala normer, och det hektiska stadslivet sågs som en osäker och ohälsosam miljö som orsakade neuroser och sämre mental hälsa. ${ }^{11}$ I och med den medicinska forskningens framsteg kunde man diagnostisera patienterna mer exakt. Speciellt två diagnoser, dementia praecox (även känd som schizofreni) och manisk-depressiv psykos, blev vanliga. Majoriteten av patienterna på mentalsjukhusen diagnostiserades med någondera av dessa och det var framför allt de här två sjukdomarna läkarna sökte botemedel för. ${ }^{12}$

\section{Hydroterapi}

Hydroterapi, eller vattenterapi, är en av de äldsta och mest varierande terapiformerna. Vattenterapi togs i bruk inom psykiatrin på r7oo-talet, blev allt mer populär under 1800 -talet och användes mycket allmänt under första hälften av 1900-talet. ${ }^{13}$ Sjukhusen kunde använda kalla duschar som behandlingsmetod, men den vanligaste formen av hydroterapi var långa bad och våta lindor eller inpackningar. Badvattnets temperatur mättes noggrant till $35-36^{\circ} \mathrm{C}$ och patienten kunde sitta i badet under flera timmars tid. Badet ordinerades av en läkare och övervakades av en skötare. Oroliga patienter fick ett nät över badkaret så att de inte skulle rymma. En patient kunde också lindas in helt eller delvis i våta lindor. När de våta lakanen torkade på patientens kropp stramades de åt och kunde kännas väldigt obekväma. Patienterna kunde ligga inpackade i flera timmar per dag, under flera dagar i rad, och en patient kunde bindas fast i sängen om hen verkade

II. Shorter, Psykiatrian historia, s. 56; Martti Kaila, Psykiatrian historia lääketieteen yleiskehityksen ja kulttuuribistorian valossa, Porvoo: W. Söderström I966, s. I58-I64.

I2. Pietikäinen, Hulluuden historia, s. 248-256; Shorter, Psykiatrian historia, s. I25.

I3. Ilkka Raitasuo, "Kylpy- ja kiedehoidot", Eero Elomaa \& Ilkka Taipale (toim.), Psykiatrian hoitomuodot I9oo-luvulla, Vantaa: Mielenterveyden keskusliitto I996, s. 4I. 
orolig. De här behandlingsmetoderna användes allmänt i Finland in på i930-talet. ${ }^{14}$

Eftersom de långa baden och inpackningarna drastiskt begränsade patienternas möjligheter att röra sig kan hydroterapin ses som en mellanform mellan disciplinär åtgärd och vård. Fokus låg på att behandla kroppen och forskaren Joel Braslow ser hydroterapin som det första ledet i utvecklingen där psykiatrisk vård under I90o-talets första hälft i allt högre grad inkräktade på patientens fysiska integritet. ${ }^{15}$

\section{Sömnterapi}

Sömnterapi, eller förlängd narkos, användes allmänt i psykiatrisk vård på 1920- och 1930-talen. Behandlingen gick ut på att patienterna sövdes ner med hjälp av mediciner, hölls nersövda i flera dagar eller veckor och väcktes endast för korta stunder för att äta eller uträtta sina behov. ${ }^{16}$ Sömnterapin kombinerades med psykoterapi och tanken var att sömnen skulle lugna patienten medan psykoterapin skulle åtgärda de psykiska problemen. ${ }^{17}$

Sömnterapin gav goda resultat vid behandlingen av akuta psykoser, men den medförde även betydande risker. Patienten kunde dö under behandlingens gång av lunginflammation, blodpropp eller kvävning som inte upptäcktes på grund av nersövningen. Det hände även att patienterna föll i koma. ${ }^{18}$ Sömnterapi användes vid de flesta finska mentalsjukhusen och även om behandlingsmetoden blev mindre vanlig när chockbehandlingarna togs i bruk, användes den på en del håll ännu efter kriget. ${ }^{19}$

Likheterna mellan sömnterapi och chockbehandlingar är stora. Båda går ut på att nollställa patienten - antingen genom sömn eller

I4. Raitasuo,"Kylpy- ja kiedehoidot", s. 42-44; Sirkka-Liisa Tuovinen, Halikon sairaala 1926-I986, Halikko: Varsinais-Suomen mielisairaanhuoltopiiri 1986.

15. Joel Braslow, Mental Ills and Bodily Cures. Psychiatric Treatment in the First Half of the Twentieth Century, Berkeley: University of California Press I997, s. II.

16. Elliot S. Valenstein, Great and Desperate Cures. The Rise and Decline of Psychosurgery and Other Radical Treatments for Mental Illness, New York: Basic Books I986, s. $34-35$.

I7. V.P. Savolainen,"Kestouniterapia”, Eero Elomaa \& Ilkka Taipale (toim.), Psykiatrian hoitomuodot 19oo-luvulla, Vantaa: Mielenterveyden keskusliitto I996, s. 5 o.

I8. Shorter, Psykiatrian historia, s. 237-24I; Savolainen, "Kestouniterapia", s. 5I.

I9. Savolainen, "Kestouniterapia", s. 54 . 
chock - och på det här viset skapa lugn och klarhet i patientens tillstånd. Båda kräver även uppmärksamhet samt noggranna förberedelser och uppföljning av läkare och skötare.

\section{Arbetsterapi}

Arbetsterapi blev en officiell terapiform på 1920-talet och på många finska mentalsjukhus var den en av de viktigaste terapiformerna. ${ }^{20}$ Det terapeutiska arbetet avvek inte från normala arbetssysslor utan bestod av till exempel trädgårdsarbete, handarbete, lantbruk och kökssysslor. Arbetsterapin förstärkte patienternas självförtroende, minskade rastlösheten och på köpet blev diverse nödvändiga arbeten i sjukhusvardagen uträttade.

Den terapeutiska poängen låg $i$ att hålla patienterna sysselsatta genom att ge dem meningsfulla uppgifter och för många var arbetet även en länk till världen utanför sjukhuset. ${ }^{21}$ Därtill var arbetsterapin ekonomiskt lönsam för sjukhusen i och med att arbetskraften var gratis och behovet att köpa in tjänster och varor minskade.

\section{Malariaterapi}

Dementia paralytica, även känd som neurosyfilis, var en skoningslös sjukdom. Sjukdomen gav sig till känna först flera år efter smittan och orsakade psykiska symptom som depression och paranoia samt demens och förlamning hos de drabbade patienterna. Syfilisdiagnosen var vanlig i patientjournalerna och ännu på I93o-talet uppskattades att ungefär en tredjedel av de nyintagna manliga medelålderspatienterna i Finland led av sjukdomen. ${ }^{22} \mathrm{Nu}$ för tiden vet man att sjukdomen orsakas av bakterier och att den kan botas med penicillin, men före den här upptäckten kom man på ett annat botemedel, nämligen malariaterapi.

Malariaterapi togs i bruk i mitten av I9Io-talet och bygger på att febern som orsakas av malaria "bränner bort" syfilisinfektionen.

20. Pietikäinen, Hulluuden historia, s. I72-I73.

21. Sirkka-Liisa Tuovinen, Inbimillinen Nikkilä. Helsingin suuri mielisairaala Sipoossa 19I4-1999, Helsinki: Helsingin kaupungin terveyskeskus 2009, s. I6o; Nickby sjukhus verksamhetsberättelse 1937, Nikkilän sairaala, Dc:I Vuosikertomukset I93I-I972, Stadsarkivet, Helsingfors.

22. Pietikäinen, Hulluuden historia, s. I2I-I22. 
Patienten smittades avsiktligt med malaria och fick genomlida ro-r6 febertoppar då febern steg till $39-40{ }^{\circ} \mathrm{C}$ innan man gav honom eller henne kinin som fick febern att gå ner. Behandlingen gav goda resultat men kunde medföra komplikationer. Malariabehandlingen togs i bruk i Finland på I920-talet och användes så sent som I956. För att få malariainfektionen var patienten tvungen att åka till antingen Lappvikens eller Gumtäkts sjukhus för könssjukdomar och där få en injektion av malariabesmittat blod. ${ }^{23}$

Malariaterapin gav resultat och blev väldigt populär. Under en kort tid hann läkarna hoppas på att även andra psykiska sjukdomar kunde botas med liknande metoder. Detta gav inspiration till att utveckla liknande behandlingar och kan ses som ett steg mot allt mer ingripande och drastiska behandlingsmetoder.

\section{HELANDE KOMA OCH BOTANDE CHOCKER}

Chockbehandlingarna - som så många andra upptäckter - kom till av en slump. På r920-talet använde den österrikiske läkaren Manfred Sakel insulin för att behandla morfinister med abstinensbesvär. Insulinet avlägsnar glukos från musklerna och Sakel märkte att små doser förbättrade patienternas tillstånd. Det gällde dock att vara noga med doseringen eftersom en överdos ledde till koma. Doseringsmisstag hände ibland, men lyckligtvis kunde situationen räddas med en glukoslösning som användes för att väcka patienterna. I samband med dessa oavsiktliga insulinkomatillstånd lade Sakel märke till att patienterna blivit kvitt sitt beroende och till på köpet blivit mycket lugnare och medgörligare. ${ }^{24}$ En av de överdoserade patienterna led förutom av abstinensbesvär även av psykos. När patienten väckts ur komatillståndet märkte Sakel att patientens psykiska symptom hade lindrats avsevärt. ${ }^{25}$ Den här upptäckten fick honom att utveckla sina

23. A. Sakari Härö, "Malaria ja muut kuumehoidot neurosyfiliksen hoitokeinona", Eero Elomaa \& Ilkka Taipale (toim.), Psykiatrian hoitomuodot I9oo-luvulla, Vantaa: Mielenterveyden keskusliitto I996, s. 76-79; Sirkka-Liisa Tuovinen, Kellokosken sairaala 1915-1990, Kellokoski: Kellokosken sairaala 1990, s. 63; besök på Törnävä sjukhusmuseum och guidad tur med Raija Kontiola 7/9 2013.

24. Shorter, Psykiatrian historia, s. $244^{-245}$.

25. Valenstein, Great and Desperate Cures, s. 47. 
behandlingsmetoder och 1933 påbörjade han ett experiment där insulinkoma användes som behandling av psykiska sjukdomar. Sakel upptäckte snart att en enda koma inte gav särskilt bra resultat och följaktligen fick patienterna i testgruppen genomgå 20-60 insulinkomatillstånd under en period på några månader. År 1934 rapporterade han om sin upptäckt i en artikel och hävdade att 70 procent av de behandlade patienterna tillfrisknat och ytterligare I8 procent blivit bättre. ${ }^{26}$ Det här var alldeles fenomenala tillfriskningssiffror inom den psykiatriska medicinen på den här tiden. Ryktet spred sig som en löpeld och snart hade insulinbehandlingarna tagits i bruk i de flesta västländerna.

Behandlingen inleddes med en cirka två veckor lång fas där man dagligen gav patienten små insulindoser. Dosen ökades varje dag tills man hittade en dosering som försänkte patienten i koma. Insulinet gjorde patienten gradvis sömnigare och slutligen föll hen i en djup, hypoglykemisk dvala som hen inte kunde väckas ur utan glukoslösning. ${ }^{27} \mathrm{I}$ den andra fasen försänktes patienten i komatillstånd 4-6 gånger $\mathrm{i}$ veckan och $\mathrm{i}$ regel avslutades behandlingen om patienten inte reagerat efter 50 behandlingsgånger. I den tredje fasen fortsatte man behandlingarna med syftet att stabilisera patientens tillstånd och i den fjärde fasen trappade man ner insulindoserna till noll under ungefär en veckas tid. ${ }^{28}$

Behandlingspraxisen varierade mycket mellan olika läkare. Patienterna kunde hållas i komatillstånd i en halv timme eller i en och en halv timme. En del patienter fick insulinchockbehandling i 2-3 månader, andra under 6-I2 månaders tid. ${ }^{29}$ De flesta läkarna verkade anse att det var viktigt att fortsätta tillräckligt länge med behandlingen för att kunna avgöra om patienten reagerade på önskat sätt. ${ }^{30} \mathrm{I}$ intervjuerna

26. Shorter, Psykiatrian historia, s. 246-247; Whitaker, Mad in America, s. 84-85.

27. A. Soininen, "Hypoglykeemisen tilan käytöstä mielitautien, erityisesti jakomielisyyden hoidossa", Duodecim I937:8, s. 745-755.

28. Eero Elomaa, "Insuliinisokkihoito", Eero Elomaa \& Ilkka Taipale (toim.), Psykiatrian hoitomuodot I9oo-luvulla, Vantaa: Mielenterveyden keskusliitto I996, s. I3.

29. A. Lappalainen \& A. Westling,"Psykiatrisesta insuliinihoidosta ja sen komplikaatioista", Suomen Lääkärilehti I959:I4, s. II6o; Pietikäinen, Hulluuden historia, s. 212; Soininen, "Hypoglykeemisen tilan käytöstä", s. 755 .

30. Martti Paloheimo,"Pitkäaikaisesta insuliinihoidosta eräissä kroonisissa jakomielitautitapauksissa", Duodecim I945:II, s. 8IO-8II. 
som jag gjorde för min avhandling pro gradu framgick det att man vid de finländska mentalsjukhusen på 1950- och I960-talen utvecklade en rutin där patienterna fick insulinchockbehandling varje vardag, men högst under tre veckors tid.

Konvulsionsbehandlingarna togs i bruk kort efter insulinbehandlingarna. Den ungerske läkaren Ladislas Joseph Meduna arbetade i slutet av i920-talet med epileptiska patienter och märkte vid obduktionerna att skadorna i epileptikernas hjärnor såg ut som en motsats till skadorna i schizofrena patienters hjärnor. Därtill hittade Meduna forskningsresultat som tydde på att schizofrena patienter sällan hade epilepsi, vilket ledde till en teori om att epilepsi och schizofreni var varandras motsatssjukdomar. Meduna var inte ensam om sina teorier men andra som jobbade med samma hypotes hade inte lyckats nå några resultat. Där andra hade använt epileptiska patienters blod och injicerat det i schizofrena patienter, ansåg Meduna att den botande effekten låg i själva konvulsionsanfallet. ${ }^{31}$

De första konvulsionsanfallen framkallade Meduna med kamfer, men han övergick snabbt till medicinen Cardiazol (i USA känd under namnet Metrazol) eftersom den framkallade konvulsionerna snabbare. ${ }^{32}$ Det verkande ämnet i Cardiazol och Metrazol var pentetrazol, och medicinen hade ursprungligen använts för behandling av hjärtsjukdomar. I Finland användes ofta det inhemska preparatet Pentazol, men både i historiker och medicinska texter har ordet cardiazol, eller på finska "kardiatsoli”, använts oberoende av vilken version av medicinen som använts för behandlingen. ${ }^{33}$ År 1935 publicerade Meduna en artikel om den nya metoden och under några år därefter reste han flitigt runt Europa och USA för att presentera sina resultat.

3I. Pietikäinen, Hulluuden historia, s. 217-218; Shorter, Psykiatrian historia, s. 2I-25.

32. Valenstein, Great and Desperate Cures, s. 49; Jesper Vaczy Kragh, "Shock Therapy in Danish Psychiatry", Medical History, 2010:54, s. 346.

33. Mauri Mattila, "Pentetratsolisokki psykoosien hoidossa", Eero Elomaa \& Ilkka Taipale (toim.), Psykiatrian hoitomuodot Igoo-luvulla, Vantaa: Mielenterveyden keskusliitto I996, s. I8; Risto Vataja,"Sähkösokkihoidon historiaa", Eero Elomaa \& Ilkka Taipale (toim.), Psykiatrian hoitomuodot I9oo-luvulla, Vantaa: Mielenterveyden keskusliitto I996, s. 28; Heljä Nenonen et al., Hoitotyötä Kellokosken sairaalassa, Tuusula: Kellokosken sairaala 1998, s. I46; R. Wilenius, ”Ns. šokkihoidon yhteydessä esiintyvistä luunmurtumista", Duodecim I948:4, s. 296; Pietikäinen, Hulluuden bistoria, s. 218-220. 
Liksom insulinbehandlingen togs även cardiazolbehandlingen emot med öppna armar, och i slutet av r930-talet hade metoden tagits i bruk vid de flesta brittiska och amerikanska sjukhus. ${ }^{34}$

Cardiazolbehandlingen var betydligt snabbare och lättare att genomföra än insulinbehandlingen. Patienten fick en cardiazolinjektion och strax därefter blev hen blek, stel och orörlig i kroppen och fick svårt att andas. Därefter började de kraftiga konvulsionerna. Patienten hade ingen kontroll över sin kropp och vårdpersonalen var tvungen att hålla fast honom eller henne så länge konvulsionerna pågick, vilket vanligen var cirka 40-6o sekunder. Efter anfallet blev patienten medvetslös, föll i en djup sömn och vaknade snart upp. Liksom vid insulinbehandlingen provade man sig fram till den rätta doseringen. Ifall den givna dosen inte framkallade konvulsioner injicerade man omedelbart mera medicin, eftersom uteblivna konvulsioner kunde leda till ett mycket smärtsamt tillstånd som kunde vara i upp till två dygn. ${ }^{35}$

Strax efter cardiazolbehandlingarna togs elchockbehandlingarna i bruk. Båda behandlingarna grundar sig på idén att epileptiska anfall, även kända som grand mal-anfall, hade en positiv inverkan på vissa former av mentalsjukdom. Den italienska läkaren Uno Cerletti hade forskat i epilepsi och när han hörde om de nya chockbehandlingarna blev han intresserad av tanken att ersätta cardiazolen med elektricitet. Han började utveckla elchockbehandlingen tillsammans med Lucio Bini och de testade sina teorier på hundar som gavs elchocker genom elektroder som var fästa vid mun och anus. Alla djur dog på grund av hjärtstillestånd. Cerletti och Bini prövade på nytt och fäste elektroderna på djurens huvud så att strömmen inte gick via kroppen och den här gången uppnådde de önskat resultat. Hundarna blev medvetslösa men innan de tuppade av fick de ett konvulsionsanfall som liknade ett epileptiskt anfall. Inspiration till den här metoden hämtade Cerletti och Bini från ett slakteri i Rom där metoden användes för att göra svinen medvetslösa före slakt. ${ }^{36}$

34. Valenstein, Great and Desperate Cures, s. 5o; Niall McCrae,"'A Violent Thunderstorm': Cardiazol Treatment in British Mental Hospitals", History of Psychiatry, volume I7, 2006:I, s. 70, https://doi.org/ro.II77/0957154Xo6061723.

35. McCrae,"'A Violent Thunderstorm", s. 71-72; Pietikäinen, Hulluuden historia, s. 2I9; Mattila, "Pentetratsolisokki psykoosien hoidossa", s. 20-2I.

36. Edward Shorter \& David Healy, Shock Therapy. A History of Electroconvulsive Treat- 
Jämfört med insulin- och cardiazolbehandlingarna var den nya metoden överlägsen i snabbhet och kostnadseffektivitet. En elchock räckte $\mathrm{O}, \mathrm{I}-\mathrm{I}$, O sekunder och även med konvulsionsfasen och återhämtningen medräknade var behandlingen snabbt över. Den första behandlingsgången räckte vanligen längre i och med att man var tvungen att testa sig fram till hur många volt el patienten behövde för att konvulsionerna skulle börja. Läkaren började med en mindre dos och patienten gavs chocker med högre volttal tills hen fick ett konvulsionsanfall. Spänningen varierade mellan 80 och 550 volt. ${ }^{37}$

Elchockerna, som började kallas electroconvulsive therapy eller ECT, spred sig snabbt från Italien till resten av Europa och över Atlanten till Nordamerika. År 194I hade 42 procent av de amerikanska mentalsjukhusen en elchockapparat och rapporterna tydde på att användningsgraden av dessa var hög och hela tiden steg. År I947 hade andelen stigit till 90 procent och det var tydligt att de amerikanska sjukhusen var snabba att övergå från de dyrare insulin- och cardiazolbehandlingarna till ECT ${ }^{38}$ Utvecklingen var liknande i Europa, men i till exempel Storbritannien och Frankrike fortsatte man aktivt med cardiazol- och insulinbehandlingar jämsides med elchockbehandlingarna. ${ }^{39} \mathrm{De}$ första elchockapparaterna anlände till Kellokoski och Lappvikens sjukhus I94I, och under åren 1942-I944 införskaffades ytterligare tio apparater. Behandlingen blev en del av mentalsjukhusens vardag. ${ }^{40}$ Inom några år hade den tagits i bruk vid så gott som alla finska mentalsjukhus. ${ }^{41}$ Krigstiden medförde brist på mat och mediciner, vilket innebar att sjukhusen var tvungna att minska på användningen av insulin- och cardiazolbehandlingar. Elchockapparaterna gjorde det möjligt för sjukhusen att fortsätta ge chockbehandlingar trots rådande resursbrist.

ment in Mental Illness, New Brunswick: Rutgers University Press 2007, s. 32-37; Vataja, "Sähkösokkihoidon historiaa", s. 28-29; Whitaker, Mad in America, s. 97.

37. Lyyli Kinnunen,"Mielisairaanhoito", Sairaanhoitajattarien oppikirja IX, Helsinki: WSOY 1943, s. I28.

38. Braslow, Mental Ills and Bodily Cures, s. roo; Shorter \& Healy, Shock Therapy, s. $79-80$.

39. McCrae,"'A Violent Thunderstorm"', s. 84.

40. Kivimäki, Battled Nerves, s. 367 .

4I. Enligt Ilmari Kalpa, "Šokkikäsittelyn vaikutuksesta mielisairaalan toimintaan", Duodecim I947:6, s. 628, användes elchocker vid 2I av 27 mentalsjukhus i Finland. 


\section{Chockbehandlingarnas inverkan på sjukhusvardagen}

Insulinchockbehandlingen krävde både tid- och personalresurser. Behandlingen inleddes vanligtvis på morgonen, dels för att patienten inte fick äta något före behandlingen, dels för att hela resten av dagen kunde ägnas åt återhämtning. Insulininjektionen gavs på morgonen och patienten föll i så kallad totalchock eller koma efter cirka I-2 timmar. Före komafasen förekom olika symptom på hypoglykemi. Patienten svettades kraftigt, blev sömnig och hade hjärtklappningar; en del fick reaktioner som liknade eufori och berusning. Vissa steg upp ur sängen, sjöng eller jollrade innan de somnade och föll i koma. Övriga symptom som kunde förekomma var koordinationssvårigheter, ryckningar och till och med epileptiska anfall. ${ }^{42}$

När patienten legat i koma den tid läkaren ordinerat väcktes hen med en glukoslösning gjord på vatten och vanligt strösocker. Lösningen gavs vanligen med en slang via näsan direkt i magsäcken. Ifall situationen krävde att patienten väcktes snabbt gavs en glukosinjektion. En del av patienterna var lugna och klara genast då de vaknade, men många var upprörda, sluddrade, grät, skrattade eller viftade oroligt omkring sig. När patienten lugnat ner sig fick hen först ta ett bad och därefter äta. ${ }^{43}$

Förutsatt att behandlingen hade inverkan var patienten som en annan människa efter den. Efter insulinchocken var patienterna vanligen omtumlade och förvirrade, och betedde sig som småbarn när de vilset sökte kontakt med skötarna och läkarna. ${ }^{44}$ När de väl återhämtat sig var deras sjukdomssymtom och förvirrade sinnestillstånd som bortblåsta. Negativa, osociala och likgiltiga patienter förvandlades till sociala och pratsamma personer som intresserade sig för sin framtid, sitt arbete och sin familj. ${ }^{45}$ Den här förbättringen i patienternas tillstånd kunde inte uppnås med andra metoder än chockbehandlingen, vilket var orsaken till att denna behandlingsmetod blev så populär.

\footnotetext{
42. Soininen, "Hypoglykeemisen tilan käytöstä", s. 758-759.

43. Kinnunen,"Mielisairaanhoito", s. Io8-Io9; Lappalainen \&Westling,"Psykiatrisesta insuliinihoidosta ja sen komplikaatioista", s. II6I-II62.

44. Intervju med Leena och Jouko Puustinen, bandad II/4 20I2, i skribentens ägo; Whitaker, Mad in America, s. 87 .

45. Soininen, "Hypoglykeemisen tilan käytöstä", s. 763 .
} 
Insulinchockbehandlingen krävde att personalen övervakade patienterna noggrant under behandlingen. En del patienter kunde få spontana epilepsianfall och ibland vaknade patienten inte trots extra glukosinjektioner. Ifall personalen inte fick situationen under kontroll kunde det uppstå skador på patientens centrala nervsystem och i värsta fall dog patienten. ${ }^{46}$ Komplikationerna kunde uppstå oväntat under en insulinbehandling som framskridit normalt. Med tiden utvecklades behandlingsmetoden och andelen patienter som dog på grund av behandlingen sjönk från cirka 5 procent till under en procent. ${ }^{47}$

I Finland var Kellokoski sjukhus först med att ta i bruk insulinchockbehandlingarna år 1936 och elva år senare användes behandlingsformen vid I8 av de totalt 27 finska mentalsjukhusen. ${ }^{48}$ Mycket av entusiasmen kring den nyfunna metoden hängde ihop med hoppet om att patientmängderna skulle minska och sjukhusvistelserna bli kortare. Mentalsjukhus var redan på den här tiden dyra i drift och det ökande antalet patienter höjde kostnaderna. Insulinbehandlingen var dyrare än de gamla terapiformerna. Personal, insulin och extra matransoner var kostsamma, men samtidigt litade man på att dessa investeringar skulle löna sig när patienterna kunde hemförlovas. Andra positiva verkningar var en markant minskning av våld och orolighet. ${ }^{49}$

Jämfört med insulinbehandlingen krävde cardiazolbehandlingen betydligt mindre tid och personalresurser, men behandlingen hade sina avigsidor. Många patienter fick benbrott som en följd av de starka muskelkramper behandlingen åstadkom; vanligast var fraktur av ryggkota och lårbenshals. Ungefär ro procent av de behandlade patienterna fick benbrott under behandlingen och ofta kunde en patient få flera frakturer under en behandling. I en av artiklarna nämns ett fall där patienten hade brutit åtta ryggkotor samtidigt och ett annat där patienten hade brutit båda lårbenshalsarna och två bröstkotor under en och samma behandlingsgång. För läkarna var det oklart varför en

46. Lappalainen \&Westling,"Psykiatrisesta insuliinihoidosta ja sen komplikaatioista", s. II64-II67.

47. Gerald N. Grob, The Mad Among Us. A History of the Care of America's Mentally Ill, Cambridge (Mass.): Harvard University Press I994, s. I82; Pietikäinen, Hulluuden bistoria, s. 2I4.

48. Elomaa, "Insuliinisokkihoito", s. I4; Kalpa, "Šokkikäsittelyn vaikutuksesta mielisairaalan toimintaan", s. 628 .

49. Kalpa, "Šokkikäsittelyn vaikutuksesta mielisairaalan toimintaan”, s. 627-63I. 
del patienters ben bröts under behandlingen medan andra klarade sig oskadda. Vårdpersonalen provade på att ge olika bedövnings- och avslappningspreparat åt patienterna före behandlingen, men trots detta kunde cardiazolbehandlingen leda till livslång invaliditet. ${ }^{50}$

En annan betydande nackdel med cardiazolbehandlingen var skräcken den orsakade patienterna. Preparatet framkallade en intensiv rädsla som infann sig under tiden mellan injektionen och konvulsionerna. Om cardiazoldosen var för liten kunde fasen mellan injektionen och konvulsionerna bli betydligt längre än avsett. Skräcken, kombinerad med de frekvent förekommande frakturerna, ledde till att patienterna var motvilliga att genomgå cardiazolbehandling. Det hände att patienter som ordinerats behandlingen försökte rymma eller springa undan personalen när de skulle få sin spruta. ${ }^{51}$ Många läkare ansåg att skräcken hade en terapeutisk effekt och att det var rädslan i kombination med konvulsionerna som ledde till de goda resultaten. Patienternas rädsla för behandlingen var också ett effektivt sätt att kontrollera deras beteende i och med att många lovade bete sig bättre om de slapp cardiazolsprutan. Cardiazol användes alltså förutom som botemedel också explicit i syfte att lugna ner patienter genom att skrämma dem och kontrollera deras beteende. ${ }^{52}$

I Finland blev cardiazolen aldrig lika populär som i till exempel Storbritannien och Danmark. Förutom benbrott och skräck orsakade behandlingen också betydande kostnader för sjukhusen i och med att preparatet var väldigt dyrt. 100 gram av medicinen kostade 4000 mark, vilket i dagens läge motsvarar cirka I 495 euro. ${ }^{53}$ Behandlingen togs i bruk under krigstiden då det var knappt om resurser och därtill var de flesta sjukhusen ännu fullt upptagna med att anamma insulin-

50. Wilenius, "Ns. šokkihoidon yhteydessä esiintyvistä luunmurtumista", s. 296-30I.

51. Pietikäinen, Hulluuden historia, s. 218-219; Shorter, Psykiatrian historia, s. 253-254; McCrae,"'A Violent Thunderstorm"', s. 78-8o; Nenonen et al., Hoitotyötä Kellokosken sairaalassa, s. I46.

52. McCrae, "A Violent Thunderstorm", s. 8I; Kragh, "Shock Therapy in Danish Psychiatry", s. 352-353.

53. Kaija Vuorio, Niuva. Niuvanniemen sairaala 1885-1952, Kuopio: Niuvanniemen sairaala 2oı, s. II3. Räknat utifrån värdet för mark år 1937 blir summan exakt I 494,80 euro, http://www.stat.fi/tup/laskurit/rahanarvonmuunnin.html\#_ga= 2.66945710.I662889544-I542999703-I625444798.I542999703 (hämtad 23/II 2OI8). 
behandlingen. ${ }^{54}$ Även insulinet var dyrt och krävde extra socker- och matransoner, så läkarna var tvungna att välja vilka patienter som kunde behandlas. Bristen på pengar var konstant.

De snabba och kostnadseffektiva elchockbehandlingarna kom som på beställning. Ur personalens synvinkel var ECT ett snabbare, effektivare och säkrare sätt att behandla patienterna. Vid en elchockbehandling hade sjukskötaren och mentalvårdaren hand om förberedelserna, men det var läkaren som tryckte på knappen eller vred på spaken som gav elchocken åt patienten. Mentalvårdarens uppgift var att hålla fast patienten under konvulsionsfasen och se till att denna inte skadade sig. Konvulsionerna var kraftiga och det kunde krävas till och med fyra personer för att hålla en patient stilla. ${ }^{55}$ Sjukskötaren såg till att apparaturen fungerade och höll elektroderna mot patientens tinningar när chocken gavs och övervakade patientens tillstånd efter behandlingen. ${ }^{56}$ Precis som insulin- och cardiazolbehandlingarna genomfördes även elchockbehandlingarna på förmiddagen. Patienten fick inte äta före behandlingen och hen skulle tömma sin blåsa, eftersom inkontinens under behandlingens gång var vanligt. Eventuella löständer skulle avlägsnas för att de inte skulle gå sönder. Patienten fick inget sömnmedel och länge avstod man också från avslappnande preparat, vilket personalen kallade för att ge elchocken "ră" eller "torr". ${ }^{57}$

Trots att elchockbehandlingarna var snabbare och säkrare än de andra behandlingsmetoderna tyckte många skötare, läkare och patienter illa om metoden. ECT framkallade inte en likadan skräck som cardiazolen, men en misslyckad chock som var för svag eller åstadkom endast en kort medvetslöshet utan konvulsioner, kunde kännas mycket obehaglig för patienten och resulterade i kraftig huvudvärk.

54. Bl.a. Mervi Kaarninen \& Pekka Kaarninen, Pitkäniemen sairaala Igoo-I99o, Pitkäniemi: Pitkäniemen sairaalan kuntainliitto I990, s. I09-Iıo; Sirkka-Liisa Tuovinen, Pälksaari 1925-1945. Piirisairaala rajan tuntumassa - sairaala sodan jaloissa, Helsinki:

S. Tuovinen I999, s. 92-94.

55. Vataja,"Sähkösokkihoidon historiaa", s. 30.

56. Etelä-Pohjanmaan sairaanhoitopiiri, Näytä lamppumme, loista yöhön ... Sairaanhoitajan työnkuvan muutokset erikoistuvassa sairaanhoidossa Etelä-Pohjanmaalla I930-I980, Seinäjoki: Etelä-Pohjanmaan sairaanhoitopiiri 2005, s. 85, Törnävä sjukhus verksamhetsberättelser 1937-I962, Törnävä sjukhusmuseums bibliotek, Seinäjoki.

57. Kinnunen, "Mielisairaanhoito”, s. I30; besök på Törnävä sjukhusmuseum, guidad tur med Raija Kontiola, 7/9 20I3, intervjuanteckningar i skribentens ägo. På finska användes orden "raakana" och "kuivana". 
Patienterna kom också ihåg hela behandlingen och de som råkat ut för misslyckade chocker motsatte sig ofta vidare behandling. ${ }^{58}$

På de finska mentalsjukhusen fanns inte separata rum där behandlingarna genomfördes, utan alla patienter som skulle få elchocker samlades i samma rum. Detta innebar att patienterna såg hur personalen och elchockapparaten närmade sig och kunde se och höra hur de andra patienterna genomgick behandlingen. Utan lugnande mediciner och vid fullt medvetande var det för många en skräckfylld upplevelse att se personalen och apparaten närma sig brits för brits. ${ }^{59}$ En del av patienterna var så rädda för behandlingen att de försökte rymma. Motsträviga patienter behandlades ogärna och i regel försökte läkarna diskutera vårdåtgärderna med patienterna, men det hände att patienterna gavs ECT mot sin vilja. ${ }^{60}$ Vårdpersonalen förhöll sig vanligen positiv till chockbehandlingarna, men många hade ändå motstridiga känslor. De intervjuade poängterade att det inte fanns andra metoder eller mediciner och att personalen prövade "med det ena och med det andra" för att förbättra patienternas tillstånd. ${ }^{61}$ Elchockerna lugnade också ner patienterna, vilket gjorde sjukhusvardagen lättare. ${ }^{62}$

\section{Patientbeskrioningar}

Insulinchockbehandlingen inledde chockbehandlingarnas tid vid mentalsjukhusen, men det har aldrig hittats någon förklaring till att behandlingen hade en god inverkan på patienterna. En tänkbar förklaring var att behandlingen försvagade den del av hjärnan som blivit för dominant på grund av patientens sjukdom och när den här delen blev svagare kunde andra delar av hjärnan återaktiveras. ${ }^{63}$ En annan förklaring grundade sig på att adrenalinsystemets verkningar gjorde

58. Vataja,"Sähkösokkihoidon historiaa", s. 30.

59. Besök på Törnävä sjukhusmuseum och intervju med Raija Kontiola 2013; intervju med Mikael Enckell, bandad 26/2 2013, i skribentens ägo.

6o. Intervju med Mikael Enckell 2013; telefonintervju med Birgit Repo 10/7 2013, intervjuanteckningar i skribentens ägo; telefonintervju med Rauha Turunen Io/5 20I3, intervjuanteckningar i skribentens ägo; besök på Törnävä sjukhusmuseum 20I3; Braslow, Mentall Ills and Bodily Cures, s. Io9-III.

6r. Intervju med Birgit Repo 2013.

62. Intervju med Birgit Repo 20I3; intervju med Pentti Rytkönen, bandad 23/3 20I2, i skribentens ägo; intervju med Leena och Jouko Puustinen 2012.

63. Pietikäinen, Hulluuden historia, s. 213. 
cellerna överkänsliga och att insulinet neutraliserade dessa verkningar. Insulinet gjorde cellerna passiva, vilket i sin tur minskade patientens sjukdomssymptom. ${ }^{64}$ Inte ens Sakel kunde förklara varför hans uppfinning fungerade, men han hade en teori om att hjärnskadan som behandlingen orsakade patienterna var grunden till de positiva resultaten. Vid obduktion av patienter som dött av insulinchockbehandling lade man märke till de omfattande hjärnskadorna. Dessa skador påminde om skador som uppkommer när hjärnan lider av syrebrist och ju fler chocker patienten hade fătt, desto större var skadorna. ${ }^{65}$

Diagnostiseringspraxisen varierade en hel del mellan olika länder. I USA diagnostiserades de flesta patienterna med schizofreni, medan man i de nordiska länderna använde sig av flera olika diagnoser. Insulinchockbehandlingen användes på många håll främst för schizofreni och vid amerikanska sjukhus kunde patienternas diagnoser till och med ändras till schizofreni på grund av att de fătt insulinbehandling. ${ }^{66}$ På finländska mentalsjukhus stirrade man mindre på patientens diagnos och behandlingen ordinerades för patienter med "diverse olika mentalsjukdomar" ${ }^{67}$

Martti Paloheimo vid Pitkäniemi sjukhus beskrev i en artikel från år 1945 fyra patienter som behandlats med chockbehandlingar. Den första patienten var en drygt 30-årig kvinna som fick kombinerad insulin- och cardiazolbehandling samt elchocker under sex behandlingsperioder i sju års tid. Paloheimo beskriver hur behandlingens verkan försvann snart efter att behandlingsperioden avslutats, vilket ledde till att behandlingsperioderna förlängdes. Sammanlagt fick patienten 354 insulinchocker, 197 cardiazolchocker och roo elchocker. Paloheimo ansåg att tillståndet man åstadkommit terapeutiskt sett var mycket betydelsefullt, även om patienten inte tillfrisknade helt och hållet. ${ }^{68}$

64. Grob, The Mad Among Us, s. I8I.

65. Whitaker, Mad in America, s. 89.

66. Deborah Blythe Doroshow,"Performing a Cure for Schizophrenia: Insulin Coma Therapy on the Wards", Journal of the History of Medicine and Allied Sciences, volume 62, 2007:2, s. 225-227, https://doi.org/IO.IO93/jhmas/jrlo44.

67. Wilenius, ”Ns. šokkihoidon yhteydessä esiintyvistä luunmurtumista”, s. 296. I den finska originaltexten används "erilaisten mielitautien". Översättning till svenska: SO.

68. Paloheimo, "Pitkäaikaisesta insuliinihoidosta eräissä kroonisissa jakomielitautitapauksissa", s. 8I2-8I4. 
Den andra patienten var en drygt 20-årig man som fick totalt 333 insulinchocker och 132 cardiazolchocker under nästan fyra års tid. Patienten hemförlovades I, 5 år efter den sista behandlingen, men dog i tuberkulos cirka två månader senare. Den tredje patienten, en ung student, gick samma öde till mötes. Han fick I 28 insulinchocker under tre års tid och skrevs ut i förbättrat tillstånd, men dog sex månader senare i tuberkulos. ${ }^{69}$

Den fjärde patienten var också en ung man i 20-årsåldern som gavs insulin-, cardiazol- och elchockbehandlingar under fem års tid. Patientens tillstånd blev bättre av behandlingarna och han blev utskriven, men han återvände till sjukhuset när behandlingarnas effekt försvann. ${ }^{70}$

Patientbeskrivningarna är intressant läsning. Före behandlingarna beskrivs patienterna bland annat som oroliga, våldsamma, autistiska, tillslutna, katatoniska, paranoida, hallucinerande, orena och aptitlösa. Under de friskare perioderna beskrivs patienterna som sakliga, flitiga och arbetsamma. Paloheimo fäster alltså särskild uppmärksamhet vid arbetslusten, renligheten och aptiten samt det besvär som patienten orsakar personalen. Som biverkningar nämns epileptisk slöhet, långsammare och trögare tal samt barnsligt känsloliv, men alla dessa förefaller ha varit acceptabla. ${ }^{71}$

Liksom i samband med insulinbehandlingen fanns det inte heller här några egentliga rekommendationer om hur ofta patienterna kunde cardiazolbehandlas. Den allmänna praxisen tycks ha varit att man fortsatte med behandlingen ifall patienten reagerade på ett önskvärt sätt och väntade tills man uppnådde återhämtning eller det var tydligt att behandlingen inte skulle ge resultat. Martti Paloheimo beskriver hur chockbehandling använts i några kroniska fall av schizofreni på Pitkäniemi sjukhus, och även om fokus tydligt låg på insulinbehandling fick patienterna också konvulsionsbehandling med cardiazol och elchocker. Exempelvis fick en patient totalt 197 cardiazolchocker under sju års tid. En annan patient hade fått $\mathrm{I} 32$ cardiazolchocker under

69. Ibid., s. 8I4-8I6.
70. Ibid., s. 8I7-8I9.
7I. Ibid., s. 8I2-8I9. 
fyra års tid och Paloheimo nämner att patienten alltid blev pigg av behandlingen. ${ }^{72}$

I Finland användes cardiazolbehandlingen vanligen som ett komplement till insulinbehandlingarna. Patienten fick först en dos insulin och när hen försjönk i en delvis insulinkoma gavs hen cardiazol. Efter cardiazolanfallet väcktes patienten på samma sätt som efter en insulinkoma, det vill säga genom att man gav sockerlösning via en slang. ${ }^{73}$ Patienterna som fick den kombinerade behandlingen hade vanligen först fått enbart insulinbehandling, men när den inte fungerade övergick läkarna till den kombinerade insulin- och cardiazolmetoden. Det verkar som om de finländska läkarna helst valde den "mjukare" insulinbehandlingen och använde den som grundbehandling. Om den inte fungerade utökades behandlingen med cardiazolchocker, som i regel var mycket färre till antalet än insulinchockerna. ${ }^{74}$

Elchockbehandlingen var effektiv och billig och användes därför i mycket större utsträckning än de andra chockbehandlingarna. Många patienter föredrog de snabba elchockbehandlingarna framför insulin- och cardiazolbehandlingarna. En nackdel med behandlingen var minnesluckorna som kunde uppstå hos en del patienter. Speciellt de som genomgått långa chockbehandlingsperioder kunde få problem med minnet. ${ }^{75}$

Tabell I visar hur många patienter på Nickby sjukhus som har behandlats med chockbehandlingar mellan 1946 och 1964 . Insulinoch cardiazolbehandlingarna togs i bruk redan 1937 , men antalet behandlade patienter nämns i verksamhetsberättelserna först från och med $1946 .{ }^{76}$ Tabellen visar tydligt att elchockbehandlingen var den mest populära av metoderna och allmänt verkar chockbehandlingarna ha använts oftast i början av 1950-talet. Strax efter mitten av

72. Ibid., s. 8I2-8I6.

73. Ilmari Kalpa,"Maanis-depressiiviseen mielisairauteen kuuluvien depressiotilojen cardiazolikäsittelystä", Duodecim I940:I2, s. 488.

74. Oinonen, Man prövade än det ena, än det andra, s. 6I-62.

75. Pietikäinen, Hulluuden historia, s. 223; intervju med Ulf-Göran Ahlfors, bandad 6/3 2013, i skribentens ägo.

76. Oinonen, Man prövade än det ena, än det andra, s. 73; Nickby sjukhus verksamhetsberättelser 1946-I964, Nikkilän sairaala, Dc:I Vuosikertomukset I93I-I972, Stadsarkivet, Helsingfors. 
Tabell 1. Patienter som fått chockbehandling på Nickby sjukhus 1946-I964.

\begin{tabular}{|c|c|c|c|c|c|c|}
\hline År & Insulin & $\begin{array}{c}\text { Cardiazol/ } \\
\text { pentazol }\end{array}$ & El & Insulin och el & $\begin{array}{c}\text { Insulin och } \\
\text { cardiazol }\end{array}$ & Totalt \\
\hline 1946 & 32 & & 149 & 15 & & 196 \\
\hline 1947 & 66 & & 64 & 54 & & 184 \\
\hline 1948 & 55 & 13 & 136 & 53 & & 257 \\
\hline 1949 & 68 & 37 & 142 & 79 & & 326 \\
\hline 1950 & 67 & 1 & 225 & 79 & 20 & 392 \\
\hline 1951 & 82 & 17 & 186 & 54 & & 339 \\
\hline 1952 & 109 & & 162 & 12 & 33 & 316 \\
\hline 1953 & 100 & 7 & 183 & 13 & & 303 \\
\hline 1954 & 91 & 12 & 392 & 9 & & 504 \\
\hline 1955 & 58 & 16 & 288 & 1 & & 363 \\
\hline 1956 & 23 & 3 & 88 & 3 & & 117 \\
\hline 1957 & 39 & & 71 & 2 & & 112 \\
\hline 1958 & 9 & & 6 & & & 15 \\
\hline 1959 & 2 & 1 & 8 & & & 11 \\
\hline 1960 & 4 & & 4 & 1 & & 9 \\
\hline 1961 & 2 & & 27 & & & 29 \\
\hline 1962 & 2 & & 23 & & & 25 \\
\hline 1963 & 2 & & 18 & & & 20 \\
\hline 1964 & 1 & & 16 & & & 17 \\
\hline
\end{tabular}

I950-talet tog man i bruk nya mediciner som minskade användandet av chockbehandlingar avsevärt. ${ }^{77}$ De här siffrorna säger inget om chockbehandlingarnas verkningar och det är omöjligt att säga hur många av de behandlade patienterna som tillfrisknade.

\section{Förskönad historia}

Tyvärr kunde chockbehandlingarna sällan helt bota patienterna. Behandlingarna ryckte patienterna ur deras sjukdom och fick dem att klarna till för en tid, men de flesta fick återfall och var tvungna att återintas på sjukhusen. Chockbehandlingarna ansågs fungera bäst på unga, nyligen insjuknade patienter, vilket enligt en del kritiker ledde till att läkarna endast valde att behandla de friskaste patienterna, de

77. Nickby sjukhus verksamhetsberättelser I957-I958, Nikkilän sairaala, Dc:I Vuosikertomukset 193I-I972, Stadsarkivet, Helsingfors. 
som hade en lindrig form av schizofreni. ${ }^{78}$ Enligt en artikel från 1937 tillfrisknade 35 av 50 patienter som haft schizofreni i högst I, 5 år efter insulinbehandling, medan behandlingen endast fungerade på 9 av 35 patienter som haft schizofreni en längre tid. ${ }^{79}$ Det visade sig även att behandlingarna fungerade bättre på manisk-depressiva och depressiva patienter än på schizofrena. ${ }^{80}$ På 1950- och 1960-talen var man medveten om att behandlingarna inte erbjöd särskilt goda resultat på längre sikt, men man fortsatte med dem i brist på bättre metoder. ${ }^{81}$ Elchockbehandlingen är den enda chockbehandlingsmetoden som levt vidare efter medicinernas ankomst och den har använts i modifierad form ännu på 2oıo-talet. Jämfört med medicinerna har elchocken en omedelbar verkan och fungerar bra på en del depressionspatienter. $\mathrm{Nu}$ för tiden ges elchockerna under narkos vilket gör behandlingen mycket behagligare för patienten. Fullständigt tillfrisknande kan behandlingen ändå inte erbjuda. ${ }^{82}$

Chockbehandlingarna utvecklades under en tid då det inte fanns några andra fungerande behandlingsmetoder för de mentalsjuka patienterna och förväntningarna på de nya metoderna var enorma. Återhämtningstalen som Sakel, Meduna samt Cerletti och Bini presenterade ingav hopp och förde psykiatrin in i en ny era, men senare har det visat sig att siffrorna de presenterade var rejält förskönade. Ladislas Medunas första cardiazolbehandlade patient hette Zoltan och hade diagnosen katatonisk schizofreni. Enligt Medunas självbiografi blev Zoltan helt återställd, men i verkligheten fick patienten återfall och återintogs på sjukhuset där han dog år $1945 \cdot{ }^{83}$ Även Cerlettis och Binis berättelse om den första elchockbehandlingen polerades en aning. Deras första elchockbehandlade patient var en schizof ren medelålders man som polisen hittat i ett förvirrat sinnestillstånd. Enligt

78. Whitaker, Mad in America, s. 90-91.

79. Soininen,"Hypoglykeemisen tilan käytöstä mielitautien, erityisesti jakomielisyyden hoidossa", s. $762-763$.

8o. Mattila,"Pentetratsolisokki psykoosien hoidossa", s. I8-20; Kalpa,"Šokkikäsittelyn vaikutuksesta mielisairaalan toimintaan", s. 483.

8I. Intervju med Leena och Jouko Puustinen 20I2; intervju med Pentti Rytkönen 2012.

82. Intervju med Ulf-Göran Ahlfors 20I3; Pietikäinen, Hulluuden historia, s. 222-223.

83. Shorter \& Healy, Shock Therapy, s. 26-28; Pietikäinen, Hulluuden historia, s. 218; Kragh, "Shock Therapy in Danish Psychiatry", s. 347. 
Cerlettis och Binis version var patienten helt återställd och frisk efter två elchocker, medan mannen i verkligheten fick flera chocker i över en veckas tid tills hans tillstånd ansågs förbättrat. Några år senare fick patienten återfall och togs in på ett mentalsjukhus. ${ }^{84}$ Även Manfred Sakels återhämtningstal verkade misstänkt höga och troligtvis trissade han upp dem i någon mån, eller tolkade begreppet "återhämtad" mer flexibelt än övriga läkare. Åtminstone tycktes ingen annan läkare nå lika goda resultat med insulinbehandling som han. ${ }^{85}$

Försköningar av det här slaget kan knappast ses som etiskt och moraliskt acceptabla men samtidigt kan man förstå att läkarna i en tid då det inte fanns några effektiva behandlingar ville få dessa nya metoder att framstå som så goda som möjligt. Chockbehandlingarna var trots allt ett stort framsteg för psykiatrin och förbättrade otaliga patienters tillstånd, om än bara tillfälligt.

84. Shorter \& Healy, Shock Therapy, s. 42-43; Pietikäinen, Hulluuden historia, s. 22I-222. 85. Pietikäinen, Hulluuden historia, s. 2 I2. 